\title{
Effects of Coordination Exercises on Brain Activation: A Functional MRI Study
}

\author{
Akito A. Mochizuki* and Eiji Kirino** \\ *Faculty of Modern Life, Department of Business Management, Teikyoheisei University \\ 2289 Uruido, Ichihara, Chiba 290-0193 Japan \\ azumanjacot@yahoo.co.jp \\ ${ }^{* *}$ School of Medicine, Juntendo University \\ 1129 Nagaoka, Izunagaoka-cho, Tagata-gun, Shizuoka 410-2211 Japan \\ [Received October 31, 2007 ; Accepted February 19, 2008]
}

\begin{abstract}
The purpose of this study was to examine the effects of coordination exercises on brain activation as measured by functional MRI. In this study, we defined coordination exercises as exercises with a greater degree of complexity and quality, as compared to the control exercises. We hypothesized that coordination tasks evoke more brain activation than control tasks, based on the attributes of coordination exercises requiring adjustment and judgment. Two experiments were designed to study the differences in the effects of brain activation between the coordination exercises and the simpler movements of the control exercises. The first experiment compared brain activation when subjects viewed video images of the coordination exercises with that when they viewed video images of the control exercises. The second experiment compared brain activation when subjects actually performed the coordination exercises with that when they performed the control exercises. These experiments demonstrated that performing and viewing coordination exercises activated the brain activities related to motor control to a much greater degree than those of the control exercises. The results of this study indicate that coordination exercises contribute to the improvement of motor activities and also cognitive control, lending support to claims for the effectiveness of coordination training in medicine as well as in sports.
\end{abstract}

Keywords: coordination exercises, functional MRI, motor control, brain activation

[International Journal of Sport and Health Science Vol.6, 98-104, 2008]

\section{Introduction}

Coordination motor abilities can be defined as the integrating abilities of muscles and neurons. The concept of coordination abilities was first advocated by Bernstein (1967). He considered coordination abilities as being the control of muscle and joint movements, and claimed the importance of coordination abilities in physical movements. Schnabel (1973) classified coordination abilities into seven factors: reaction, rhythm, balance, orientation, coupling, transformation and differentiation. A great amount of literature on coordination has focused predominantly on motor control (Lagarde, et al., 2005; Vangheluwe, Wenderoth \& Swinnen, 2005; Forner-Cordero, et al., 2007). Several studies have been carried out on the relationship between coordination abilities and child development (Zimmermann, Schnabel \& Blume, 2002; Kirino \&
Azumane, 2004; Lyakh \& Sadowski, 2006). For the growth of a child, coordination training strengthens muscle tissue and the cardio-respiratory system, as well as the network of the central nervous system. In the field of kinesiology, the organizational principle of symmetry has been studied in the neural control of complex movements from the viewpoint of coordination ( $\mathrm{Li}$, et al., 2005). All of these studies deal with the relationship between coordination abilities and physical movements. In sports, coordination exercises are useful in developing the following functions: quick and accurate data processing, the formation of schema in the acquisition of movements, and motor control for the achievement of a specific task.

In the medical field, the usefulness of coordination training has been reported in several studies in two limited areas: the prevention of falls and rehabilitation (Oster, et al.,1997; Franssen, et al., 
1999; Rebel, 2000; Yokohata, 2002; Cauraugh, 2004; Kakebeeke, Roy \& Largo, 2006). Most of these medical-related studies have been limited to the application of coordination training to rehabilitation. It has been reported that early diagnosis and treatment of conditions that can jeopardize limb coordination, as well as coordination training, might help cognitively impaired older people to maintain optimal function (Franssen, et al., 1999). Sports therapy or dance therapy that includes elements of coordination training has been clinically useful in the treatment of psychiatric disorders. However, the effect of coordination abilities on mental conditions has not been systematically studied.

Coordination abilities require the integration of a network for information processing in the central nervous system, including visual and auditory perception, labyrinthine sense, cutaneous sensation and kinesthesia. Based on these attributes, we hypothesized that coordination tasks evoke more brain activation than simple motor tasks. There are some studies which have provided behavioral and functional MRI data on skilled motor performance (Sadato, et al., 1997; Hund-Georgiadis \& von Cramon, 1999; Jantzen, Steinberg \& Kelso, 2004; Kraft, et al., 2007). Karni, et al., (1998) showed that even a limited training experience could induce behaviorally significant changes in brain activity. We were interested in observing how coordination exercises differ from simple movements with respect to the brain activities related to motor control.

The purpose of the present study was to examine the effects of coordination exercises on brain activation measured by functional MRI (fMRI). All the movements including control exercises in this study require coordination abilities. In this study, we defined the coordination exercises as exercises with a greater degree of complexity and quality compared to the control exercises. We hypothesized that coordination tasks evoke more brain activation than control tasks, based on the attributes of coordination exercises requiring adjustment and judgment, as defined in this study. The two experiments on motor control were designed to study differences in the effects of brain activation between the coordination exercises and the control exercises consisting of simple movements. The first experiment on motor control compared brain activation when subjects viewed video images of coordination exercises with that when they viewed the video images of the simple movements. The second experiment on motor control compared brain activation when subjects actually performed the coordination exercises with that when they carried out the control exercises. We were interested in testing the hypothesis that viewing or performing coordination exercises evokes more brain activation than viewing or performing simple movements.

\section{Subjects and Methods}

\subsection{Subjects}

Thirteen healthy college students ( 5 males and 8 females, $21.2 \pm 1.2$ years old) participated in Experiments I and II. They were all Japanese undergraduate students who were not athletes. After a complete description of the study was given to them, they gave informed consent for the protocol.

\subsection{Experimental design}

The fMRI sessions were held at Juntendo University Hospital. In all fMRI sessions, a blocked design (Box-car) was employed (Figure 1). Each stimulus was presented against a white background that subtended at a visual angle of $5.4^{\circ} \times 5.4^{\circ}$. A computer was used to control stimulus timing and presentation. Visual stimuli were delivered to an active matrix LCD (Liquid Crystal Display) panel and back-projected onto a translucent screen mounted on the patient gurney of the scanner. The subjects viewed the stimuli through a mirror mounted in the head coil.

\subsection{Experimental tasks}

\subsubsection{Experiment I: Viewing}

Experiment I aimed to assess the effects of imagining coordination exercises and control exercises on brain activation at the time of viewing the video images. The subjects were instructed to imagine that they were performing training while viewing video images of coordination exercises and control exercises which were projected onto the LCD panel. Coordination exercises were those exercises which required judgment regarding the given tasks and adjustments to changes in the situation, while the corresponding control exercises needed little adjustment or judgment. In this experiment, we 


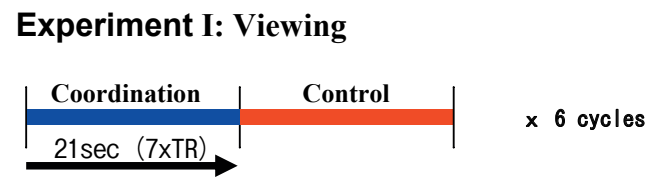

\section{Experiment II: Performing}
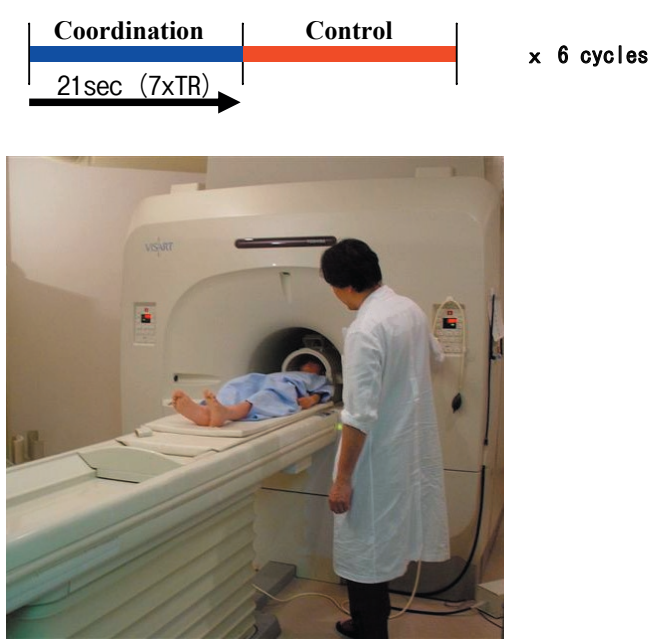

Figure 1 Tasks during fMRI

In all fMRI sessions, a blocked design (Box-car) was employed. In Experiment I, the subjects were instructed to imagine that they were performing training while viewing video images of coordination exercises and control exercises which were projected onto an LCD panel. In Experiment II, the subjects performed exercises in the MRI system, following a timing instruction prompt projected onto an LCD panel.

employed three types of coordination exercises and three corresponding control exercises. The three types of coordination exercises were: the movement of bouncing a ball, turning around and catching the ball (Type 1); stepping forward on one foot and alternately jumping forward on two feet (Type 2); and, two persons passing two balls to each other. One person bounced a ball and then passed it, and the other passed and received the ball from the first person (Type 3). The three types of control exercises, corresponding to each of the coordination exercises were: the movement of bouncing a ball (Type 1); stepping forward on one foot (Type 2); and, two persons passing two balls simultaneously (Type 3 ).

\subsubsection{Experiment II: Performing}

Experiment II aimed to assess the effects of performing coordination exercises and control exercises on brain activation. The subjects performed exercises in the MRI system following timing instruction prompts projected onto the LCD panel.
In this experiment, we employed two coordination exercises and two control exercises. The two types of coordination exercises selected were ones which are frequently used in clinical situations. The two types of coordination training were: finger tapping using two hands simultaneously (Type 1) and one person playing paper, scissors, stone using two hands such that the right hand won all the time versus the left hand (Type 2). There were two types of control exercises, corresponding to each of the coordination exercises: palm opening and closing (Type 1) and both hands playing paper, scissors, stone, performing exactly the same motions (Type 2).

\subsection{Image acquisition}

In Experiments I and II, the imaging session [252 s (84 TR) in total] consisted of 12 blocks with a duration of $21 \mathrm{~s}(7 \mathrm{TR})$, with 6 cycles $\times 2$ categories, each of which consisted of the presentation or instruction of the coordination exercises or the corresponding control exercises. The coordination exercises and control exercises were presented or indicated alternately six times.

The MRI images were acquired using a 1.5 Tesla Toshiba VISART EX system with a standard quadrature head coil and ANMR echoplanar subsystem. The subject's head was positioned along the canthomeatal line and immobilized. T1-weighted sagittal scans were used to select 13 contiguous axial slices covering the entire cortex. Functional images were acquired using a gradient-echo echoplanar sequence $(\mathrm{TR}=3000 \mathrm{~ms}$ TE $=45 \mathrm{~ms}$, Matrix $=96 \times 96$, Slice thickness $=8 \mathrm{~mm}, \mathrm{Gap}=1.0 \mathrm{~mm}$, Slice $\#=13$, $\mathrm{FOV}=260 \mathrm{~mm}$, Flip angle $=70^{\circ}$ ). Prior to each image scan, images equivalent to 2 TR $(6 \mathrm{~s})$ were acquired and discarded to allow longitudinal magnetization to reach equilibrium.

\subsection{Statistical analysis of imaging results}

\subsubsection{Individual maps}

Slice timing, motion correction of functional images, co-registration with structural data, spatial normalization to the Montréal Neurological Institute (MNI) EPI image template using a non-linear basis function, and smoothing $(8 \mathrm{~mm}$ Gaussian filter), as well as statistical analysis, relied on the SPM99 software package (Wellcome Institute of Cognitive Neuroscience, London, UK). The 


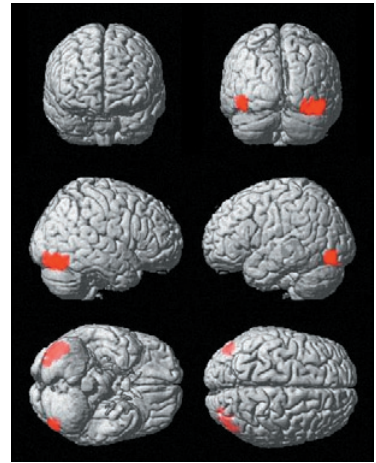

Type 1

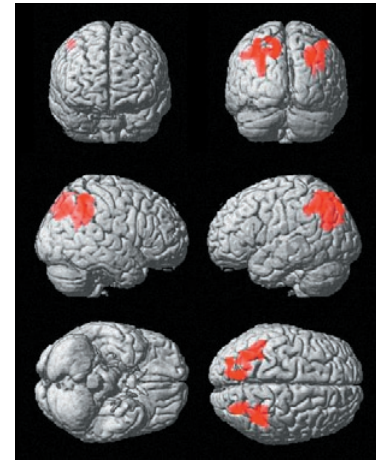

Type 2

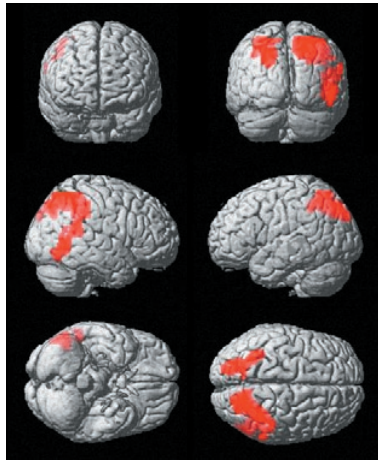

Type 3

Figure 2 Results of Experiment I

The subjects exhibited eminent activations for coordination exercises as compared to control exercises, in all of the following areas: (Type 1) right occipital frontal gyrus, left occipital lobe; (Type 2) left superior parietal lobe (BA 7), right inferior parietal lobe (BA 40); (Type 3) right precuneus, left superior parietal lobe (BA 7), and right middle temporal gyrus.

Table 1 Areas significantly responding to coordination training relative to control exercises in Experiment I.

\begin{tabular}{|c|c|c|c|c|c|}
\hline $\begin{array}{l}\text { Type of } \\
\text { coordination } \\
\text { training }\end{array}$ & Region (BA) & $\begin{array}{l}\text { Talairach } \\
\text { coordination }(\mathrm{X}, \\
\mathrm{Y}, \mathrm{Z}) \text { of peak } \\
\text { location }\end{array}$ & $\begin{array}{l}p \text {-value } \\
\text { (corrected, } \\
\text { cluster } \\
\text { level) }\end{array}$ & $\begin{array}{l}t \text {-value } \\
\text { (voxel } \\
\text { level) }\end{array}$ & $\begin{array}{l}\text { Number } \\
\text { of } \\
\text { significant } \\
\text { voxels }\end{array}$ \\
\hline \multirow[t]{2}{*}{ Type 1} & $\begin{array}{l}\text { Right occipital frontal } \\
\text { gyrus }\end{array}$ & $34,-80,18$ & 0.000 & 9.80 & 607 \\
\hline & Left occipital lobe & $-44,-78,-12$ & 0.025 & 6.21 & 178 \\
\hline \multirow[t]{2}{*}{ Type 2} & $\begin{array}{l}\text { Left superior parietal } \\
\text { lobe (BA 7) }\end{array}$ & $-34,-66,44$ & 0.000 & 8.18 & 1275 \\
\hline & $\begin{array}{l}\text { Right inferior parietal } \\
\text { lobe (BA 40) }\end{array}$ & $38,-46,36$ & 0.001 & 5.34 & 1106 \\
\hline \multirow[t]{3}{*}{ Type 3} & Right precuneus & $22,-62,50$ & 0.000 & 13.10 & 2062 \\
\hline & $\begin{array}{l}\text { Left superior parietal } \\
\text { lobe (BA 7) }\end{array}$ & $-30,-56,50$ & 0.000 & 9.55 & 994 \\
\hline & $\begin{array}{l}\text { Right middle temporal } \\
\text { gyrus }\end{array}$ & $50,-56,8$ & 0.000 & 8.10 & 847 \\
\hline
\end{tabular}

statistical significance of brain activation was evaluated based on voxelwise signal changes using the general linear model and random effects analysis in SPM99 (Friston, et al., 1998; Holmes \& Friston, 1998). A typical boxcar model convolved with a hemodynamic response function of SPM was used. Confounding effects of fluctuations in the global mean were removed by proportional scaling. Low-frequency noise was eliminated by applying a high-pass filter ( 0.375 cycles per min). Voxel values for task-versus-control contrast yielded a statistical parametric map of $t$-statistics which were then normalized to $z$ scores. Furthermore, a contrast between the average results of Experiment I and those of Experiment II was created in an identical procedure. A corresponding contrast image for each subject was also created for group analysis.

\subsubsection{Group maps}

After generating all the subjects' images, we used a one-sample $t$-test to compare task versus control conditions in Experiments I and II. We also compared viewing (Experiments I) and performing (Experiments II) coordination training. The coordinates of the most significantly active voxels (voxel size $2 \times 2 \times 2 \mathrm{~mm}$ ) in these group results were then used to create activation maps of all the brain regions. Statistical analysis considered $p<0.001$ (uncorrected) at voxel level as the relevant threshold of significance. To correct for multiple comparisons across brain volume, an extension threshold was introduced at cluster level ( $p<0.05$ corrected). The VOTL database (The Research Imaging Center at the University of Texas Health Science Center) was used to determine the Broadmann areas (BAs), corresponding to the Talairach coordinates.

\section{Results}

\subsection{Experiment I}

The coordination exercises versus control exercises contrast images are shown in Figure 2. On average, the subjects exhibited eminent activations for coordination exercises as compared to control exercises, in all of the following areas (Table 1): (Type 1) right middle occipital gyrus, left occipital lobe; (Type 2) left superior parietal lobe (BA 7), 


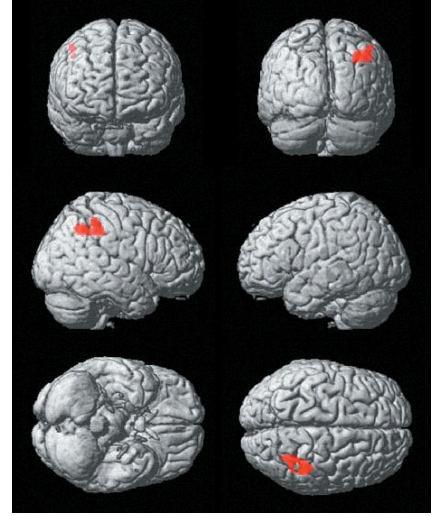

Type 1

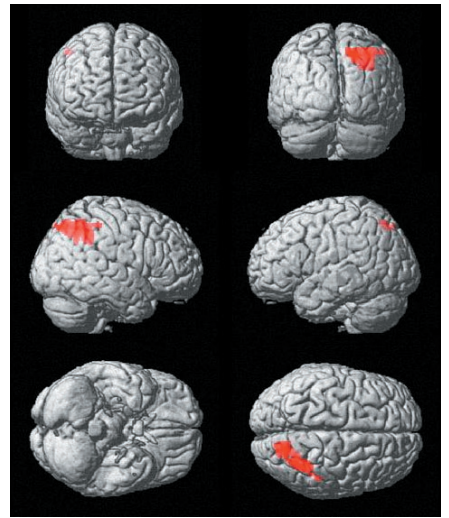

Type 2
Figure 3 Results of Experiment II

The subjects exhibited eminent activations for coordination exercises as compared to control exercises in the right inferior parietal lobe (Type 1) and right parietal lobe (Type 2).
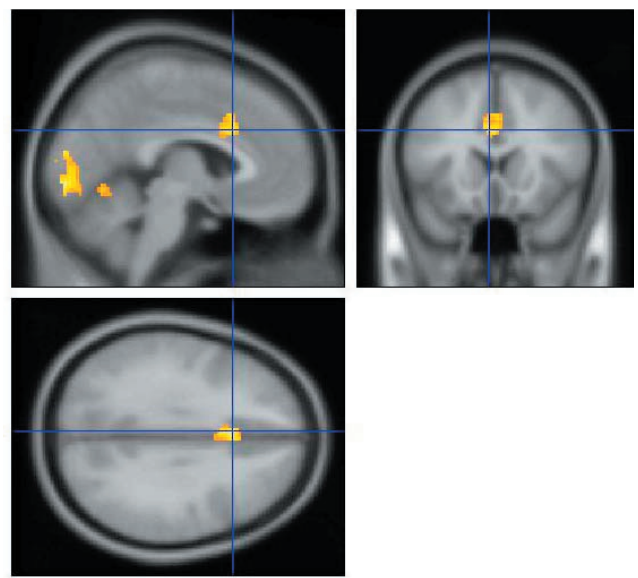

Figure 4 Experiment I versus Experiment II

Greater activation was observed in the left lingual gyrus and left cingulate gyrus (BA 32) in Experiment II, compared with Experiment I.

right inferior parietal lobe (BA 40); (Type 3) right precuneus, left superior parietal lobe (BA 7), and right middle temporal gyrus. Regarding the type of coordination exercises, Type 3 exhibited conspicuous brain activation, as compared to the other two coordination exercises. Type 3 was the most complicated movement, involving more than one person participating, and it also included information processing of changes in the situation.

\subsection{Experiment II}

The coordination exercises versus control exercises contrast images are shown in Figure 3. The subjects exhibited eminent activations for the coordination
Table 2 Areas significantly responding to coordination training relative to control exercises in Experiment II.

\begin{tabular}{|l|l|l|l|l|l|}
\hline $\begin{array}{l}\text { Type of } \\
\text { coordination } \\
\text { training }\end{array}$ & Region & $\begin{array}{l}\text { Talairach } \\
\text { coordination }(X, \\
\text { Y, Z) of peak } \\
\text { location }\end{array}$ & $\begin{array}{l}p \text {-value } \\
\text { (corrected, } \\
\text { cluster } \\
\text { level) }\end{array}$ & $\begin{array}{l}t \text {-value } \\
\text { (voxel } \\
\text { level) }\end{array}$ & $\begin{array}{l}\text { Number } \\
\text { of } \\
\text { significant } \\
\text { voxels }\end{array}$ \\
\hline Type 1 & $\begin{array}{l}\text { Right inferior parietal } \\
\text { lobe }\end{array}$ & $38,-40,40$ & 0.002 & 5.73 & 259 \\
\hline Type 2 & Right parietal lobo & $14,-74,50$ & 0.002 & 5.41 & 569 \\
\hline
\end{tabular}

Table 3 Areas significantly responding to performing relative to viewing coordination training.

\begin{tabular}{|l|l|l|l|l|c|}
\hline & Region & $\begin{array}{l}\text { Talairach } \\
\text { coordination }(X, \\
Y, Z \text { ) of peak } \\
\text { location }\end{array}$ & $\begin{array}{l}p \text {-value } \\
\text { (corrected, } \\
\text { cluster } \\
\text { level) }\end{array}$ & $\begin{array}{l}\mathrm{t} \text {-value } \\
\text { (voxel } \\
\text { level) }\end{array}$ & $\begin{array}{l}\text { Number } \\
\text { of } \\
\text { significant } \\
\text { voxels }\end{array}$ \\
\hline $\begin{array}{l}\text { performing } \\
>\text { viewing }\end{array}$ & $\begin{array}{l}\text { Left lingual gyrus } \\
\text { (BA18) }\end{array}$ & $-10,-90,-14$ & 0.000 & 7.86 & 362 \\
& $\begin{array}{l}\text { Left anterior cingulate } \\
\text { cortex (BA 32) }\end{array}$ & $-4,18,30$ & 0.002 & 6.71 & 235 \\
\hline
\end{tabular}

exercises compared to the control exercises, in the right inferior parietal lobe (Type 1) and right parietal lobe (Type 2) (Table 2). Regarding the tasks, the coordination exercises, Type 1 and Type 2, did not show any significant difference in brain activation. This can be interpreted as showing that the two tasks were similar because of the restrictions of space and the level of difficulty.

Experiment II exhibited greater activation in the left lingual gyrus (BA 18) and left anterior cingulate cortex (ACC) (BA 32) compared with Experiment I (Figure 4, Table 3).

\section{Discussion}

The present study showed that coordination exercises and control exercises differed in regard to the effects of brain activation assessed by fMRI. In Experiment I, we observed a difference in brain activation between viewing the coordination exercises and the control exercises in the middle temporal gyrus, the parietal lobe, and the occipital lobe, including the precuneus. In this experiment, the subjects watched the dynamic movements of the whole body in both kinds of exercises.

The visual system has been divided into two main streams (VanRullen, 2005): the dorsal stream, 
including the parietal lobe, where information about motion and spatial relationships among objects is represented; and the ventral stream, including the temporal gyrus, which is concerned primarily with identifying the category of objects. The occipital lobe constitutes parts of both streams. Coordination training requires the coordination of both streams. Furthermore, the activated areas in viewing the coordination training contained V5, classically referred to as the visual-motion selective area; an area that correlates with mental imagery of motion (Goebel, et al., 1998). Experiment I required the subjects not only to view the exercise, but also to mentally imagine the motion. The conspicuous difference in brain activation between the coordination exercises and control exercises might be interpreted as stemming from the degrees of complexity involved in the exercises.

Turning to Experiment II on motor control, we observed differences in brain activation between performing the coordination exercises and control exercises in the parietal lobe, the occipital lobe including the lingual gyrus, and in the prefrontal cortex (PFC) including the ACC. In this experiment, the subjects performed peripheral and local movements in both exercises.

Both performing and viewing the coordination training activated the occipital lobe and the parietal lobe. In addition, the $\mathrm{PFC}$ region was activated during performing in Experiment II. The PFC may be involved in the mapping of stimuli to appropriate responses within a particular task or context (McCarthy, et al., 1997; Kirino, et al., 2000), which is required in the coordination exercises. In particular, the ACC detects conditions in which errors are likely to occur (Carter, et al., 1998); that is, the ACC is the locus of the higher function of execution or inhibition of unnecessary movements. Activation in the PFC, including the ACC, in performing may be attributed to the larger load in the execution of coordination movements or the inhibition of unnecessary movements, compared with the condition in only viewing them.

Both viewing and performing the coordination exercises showed conspicuous brain activation, as compared to the control exercises. The above-mentioned regions in the brain that were activated, either via viewing or performing coordination training, are critically involved in the processing of visual information and the integration of perception and movement. Concretely, coordination exercises involve information processing, judging appropriate options and integrating movements corresponding to specific situations, while control exercises of simple movements tend to be routinized and do not require a great degree of mental activity.

In summary, the coordination exercises employed in the present study contributed to not only an improvement in coordination abilities at a motor level but also to a greater degree of mental activity. This leads to a new concept of physical training involving coordination training in order to influence the mental condition of a person. Thus, this fMRI study documented the possibility of the application of coordination exercises for not only the improvement of motor activities but also for that of cognitive control, lending support to claims for the effectiveness of coordination training in medicine as well as in sports.

\section{References}

Bernstein, N.A. (1967). The Co-ordination and Regulation of Movements. Oxford, UK: Pergamon Press.

Carter, C.S., Braver, T.S., Barch, D.M., et al., (1998). Anterior cingulate cortex, error detection and the online monitoring of performance. Science, 280(5364): 747-749.

Cauraugh, J.H. (2004). Coupled rehabilitation protocols and neural plasticity: Upper extremity improvements in chronic hemiparesis. Restor Neurol Neuroscience, 22(3-5): 337-347.

Forner-Cordero, A., Levin, O., Li, Y., \& Swinnen, S.P. (2007). Posture control and complex arm coordination: Analysis of multijoint coordinative movements and stability of stance. Journal of Motor Behavior, 39(3): 215-226.

Franssen, E.H., Souren, L.E., Torossian, C.L., \& Reisberg, B. (1999). Equilibrium and limb coordination in mild cognitive impairment and mild Alzheimer's disease. Journal of the American Geriatrics Society, 47(4): 463-469.

Friston, K.J., Fletcher, P., Josephs, O., Holmes, A., Rugg, M.D., \& Turner, R. (1998). Event-related fMRI: Characterizing differential responses. Neuroimage,7: 30-40.

Goebel, R., Khorram-Sefat, D., Muckli, L., Hacker, H., \& Singer, W. (1998). The constructive nature of vision: Direct evidence from functional magnetic resonance imaging studies of apparent motion and motion imagery. Eur J Neurosci, 10: $1563-1573$.

Holmes, A., \& Friston, K.J. (1998). Generalizability, random effect, and population inference. Neuroimage,7: 757.

Hund-Georgiadis, M., \& von Cramon, D.Y. (1999). Motor-learning-related changes in piano players and non-musicians revealed by functional magnetic-resonance signals. Experimental Brain Research, 125: 417-425.

Jantzen, K.J., Steinberg, F.L., \& Kelso, J.A.S. (2004). Functional MRI reveals the existence of modality and coordination-dependent timing networks. Neuroimage, 22: 1031-1042. 
Kakebeeke, T.H., Roy, S.H., \& Largo, R.H. (2006). Coordination training in individuals with incomplete spinal cord injury: Consideration of motor hierarchical structures. Spinal Cord, 44(1): 7-10.

Karni, A., Meyer, G., Rey-Hipolito, C., Jezzard, P., Adams, M.M., Turner, R., \& Ungerleider, L.G. (1998). The acquisition of skilled motor performance: Fast and slow experience-driven changes in primary motor cortex. Proc. National Academy of Sciences, 95: 861-868.

Kirino, E., \& Azumane, A. (2004). Functional MRI study of coordination training. Coordination Motor Abilities in Scientific Research, 4: 377-382.

Kirino, E., Belger, A., Goldman-Rakic, P., \& McCarthy, G. (2000). Prefrontal activation evoked by infrequent target and novel stimuli in a visual target detection task: An event-related functional magnetic-resonance imaging study. Journal of Neuroscience, 20: 6612-6618.

Kraft, E., Chen, A.W., Flaherty, A.W., Blood, A.J., Kwong, K.K., \& Jenkins, B.G. (2007). The role of the basal ganglia in bimanual coordination. Brain Research, 1151: 62-73.

Lagard, J., Peham, C., Licka, T.,\& Kelso, J.A.S.(2005). Coordination dynamics of the horse-rider system. Journal of Motor Behavior, 37(6): 418-424.

Li, Y., Levin, O., Forner-Cordero, A., \& Swinnen, S. P. (2005). Effects of interlimb and intralimb constraints on bimanual shoulder-elbow and shoulder-wrist coordination patterns. Journal of Neurophysiology, 94: 2139-2149.

Lyakh, V., \& Sadowski, J. (2006). Problems of coordination fitness control in sports. Coordination Motor Abilities in Scientific Research, 4: 70-82.

McCarthy, G., Luby, M., Gore, J., \& Goldman-Rakic, P. (1997). Infrequent events transiently activate human prefrontal and parietal cortex as measured by functional MRI. Journal of Neurophysiology, 77: 1630-1634.

Oster, P., Hauer, K., Specht, N., Rost, B., Baertsch, P., \& Schlierf, G. (1997). Strength and coordination training for prevention in the elderly. Gerontology and Geriatric Journal (Journal of the German Association of Gerontology and Geriatric), 30(4): 289-292 (in German).

Rebel, M. (2000). Coordination training after anterior cruciate ligament surgery. Sportverletz Sportschaden, 14(1): 12-19.

Sadato, N., Ibabez, V., Campbell, G., Deiber, M.P., Bihan, D.L., \& Hallet, M. (1997). Freqency-dependent changes of regional cerebral blood flow during finger movements: Functional MRI compared to PET. Journal of Cerebral Blood Flow and Metabolism, 17(6): 670-679.

Schnabel, G. (1973). The coordinative competence and the problem of agility. Theory and Practice of Physical Education, 22(3): 263-269 (in German).

Vangheluwe, S., Wenderoth, N., \& Swinnen, S.P. (2005). Learning and transfer of an ipsilateral coordination task: Evidence for a dual-layer movement representation. Journal of Cognitive Neuroscience, 17(9): 1460-1470.

VanRullen, R. (2005). Visual saliency and spike timing in the ventral visual pathway. Burlington, MA: Elsevier Academic Press.

Yokohata, Y. (2002). Rehabilitation for osteoarthritis. Clin Calcium, 12(1): 117-123.

Zimmermann, K., Schnabel, G., \& Blume, D. (2002). Coordinative competence. In Gunrun \& Bernd Ludwig (Eds.), Coordinative competence (pp. 25-33). Kassel, Germany: University Library Kassel (in German).

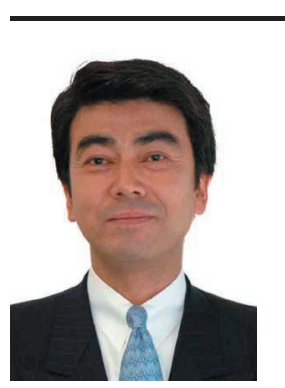

\section{Name:}

Akito A. Mochizuki

\section{Affiliation:}

Faculty of Modern Life, Department of Business Management, Teikyoheisei University

\section{Address:}

2289 Uruido, Ichihara, Chiba 290-0193 Japan

\section{Brief Biographical History:}

1984- Master's Program in Health and Physical Education, Juntendo University

1984- School of Sports and Health, Juntendo University

2007- Visiting Scientist, Pilsudski University of Physical

Education, Poland

2008- Associate Professor, Faculty of Modern Life, Department of Business Management, Teikyoheisei University

Main Works:

- Functional MRI Study of Coordination Training,Coordination Motor Abilities in Scientific Research: 377-382, 2005 (E.

Kirino)

- Coordination Training for Ball Sports, Meijitosyo, 2007

Membership in Learned Societies:

- Japan Society of Physical Education, Health and Sport Sciences

- Japanese Society of Clinical Sports Medicine

- International Association of Sport Kinetics 